\title{
Saúde da Família: \\ espaço de reflexão e de contra-hegemonia
}

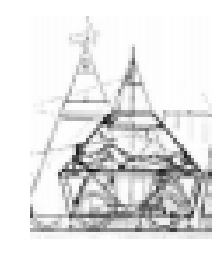

Family Healthcare: space for reflection and counter-hegemony

Jairnilson Silva Paim 1

\section{Introdução}

O texto de Campos \& Belisário contemplando certos desafios para a formação e educação permanente em Saúde da Família estimula a reflexão sobre limites e possibilidades da reorganização das práticas de saúde no Brasil, bem como sobre a constituição dos sujeitos.

Os autores revisam a emergência e o desenvolvimento do movimento ideológico da "Medicina Familiar", realçando os principais traços que marcaram as tentativas de sua difusão entre instituições de ensino e de serviços de saúde no país nas décadas de setenta e oitenta. Ao admitirem que tal movimento foi assimilado como política de governo, através da formulação do Programa de Saúde da Família (PSF), os autores assinalam a pertinência de democratizar a sua discussão conceitual.

Nesse particular, o texto fornece elementos significativos para alimentar tal debate. Mais que uma discussão conceitual, trata-se de efetuar análises políticas no sentido de orientar o que fazer em relação à expansão do programa e às necessidades de formação e educação permanente. Este é o propósito dos comentários a seguir.

\section{Da "Medicina Familiar" à construção do PSF}

Os embates político-ideológicos sobre "Medicina de Família", ocorridos nos anos oitenta, já apontavam as estratégias e indicavam os mecanismos da passagem de um movimento ideológico para uma ação política (Paim, 1986). Evidentemente que nem todo movimento ideológico se transforma em política de governo. Muitas dessas propostas podem ser assimiladas em conjunturas específicas a partir da ação política de atores sociais, ainda que submetidas ao filtro de uma seletividade estrutural do Estado Capitalista (Offe, 1984).

\footnotetext{
${ }^{1}$ Professor Titular em Política de Saúde do Instituto de Saúde Coletiva da Universidade Federal da Bahia. Pesquisador 1-A do CNPq.
} 
No que tange à Reforma Sanitária, seu tortuoso processo de implantação valorizou certos componentes do sistema de serviços de saúde tais como o financiamento, a gestão, a organização e a infra-estrutura. Contudo, a questão do cuidado, inscrita nos modelos de atenção, foi secundarizada, como política de governo.

A noção de distrito sanitário (DS) e a reflexão sobre trabalho programático em saúde (Schraiber, 1990; Paim, 1993) representaram iniciativas pioneiras para pensar a questão assistencial. Portanto, a concepção brasileira de DS não se superpunha à proposta de SILOS (OPS, 1990; Silva Junior, 1998). Ainda que a concepção de distritos sanitários no Brasil pudesse se aproximar da noção de SILOS por enfatizar o nível local, a perspectiva de mudança do modelo de atenção, mediante a reorganização das práticas de saúde na sua articulação com as demais práticas sociais e considerando as suas dimensões econômica, política e ideológica, configurava uma distinção significativa em relação ao "anódino" SILOS, no dizer de Campos \& Belisário.

Mudada a conjuntura após a $9^{\text {a }} \mathrm{CNS}$, uma nova correlação de forças permitiu iniciativas mais avançadas como a política de descentralização das ações e serviços de saúde através da NOB-93 (Brasil, 1993) e o desenvolvimento da proposta do PSF. O reconhecimento da experiência exitosa de Niteroi no que se refere a assistência à saúde da família (Silva Junior, 1998) e a ação técnico-política de atores institucionais que ampliaram o escopo do PSF, articulando-o com as propostas de distritalização e de vigilância da saúde, permitiram concebê-lo como indutor de mudanças do modelo assistencial (Cordeiro, 1996; Levcovitz \& Garrido, 1996). A opção por estruturar "equipes de saúde da família" distanciava-se, portanto, do movimento do "Médico de Família", ainda que reforçasse alguns elementos da proposta original como a humanização do cuidado e o vínculo entre serviços e usuários.

\section{O PSF como Política de Saúde}

A formulação e a implantação do PSF nos seus primeiros anos de existência suscitou inquietações e críticas diversas. De um lado, a preocupação com a tentativa de ressurreição do médico de família, não só pelo conteúdo ideológico que conformava a proposta subordinada ao movimento nos EUA, mas também pelo seu potencial anacronismo face à complexidade tecnológica da medicina moderna $e$ às formas hegemônicas da prática médica, seja no setor público, seja no privado. De outro lado, a possibilidade de que tal programa, enquanto continuação do PACS, expressasse políticas de focalização propostas pelo Banco Mundial e outros organismos internacionais, caracterizando "pacotes básicos" de atenção médica para pobres, contraditórios aos princípios de universalidade, integralidade $e$ eqüidade do SUS, ampliava a suspeição contra o PSF.

Do mesmo modo, o fato de autoridades de saúde declararem que o PSF representaria o novo modelo assistencial do SUS, indicava uma compreensão equivocada posto que uma situação de saúde tão heterogênea e complexa como a da população brasileira não se enquadraria em um único 
modelo por mais "novo" que fosse.

Apesar da relevância da ampliação do PSF faltam, contudo, evidências que apontem esse programa como estratégia suficientemente eficaz para a reorientação dos modelos assistenciais dominantes ou mesmo como "política de governo". Esta continua sendo a política de ajuste estrutural com estabilização monetária, ou seja, a saúde da moeda e não a saúde da população.

Os esforços atuais de transformação do PSF em estratégia voltada para a mudança dos modelos de atenção começa a apresentar sinais de concretização em municípios que apostaram na proposta, articulando-a ao projeto da Reforma Sanitária. Vitória da Conquista (BA), por exemplo, está redefinindo os níveis secundário e terciário, com uma regulação do setor privado, a partir da reorganização da atenção básica.

\section{Formação e Educação Permanente em Saúde da Família}

A criação de milhares de postos de trabalho pelo PSF num tempo relativamente curto impõe a busca de soluções criativas através dos Pólos de Capacitação em Saúde da Família, no sentido de utilizar, da forma mais eficiente possível, a capacidade instalada das universidades e dos serviços de saúde. O diálogo e a pactuação com instituições de ensino, a partir de propostas concretas de trabalho articulado, parecem inadiáveis.

Nesse sentido, não bastam as exortações para a escola médica se reatualizar em função de uma política de saúde. O discurso da mudança da educação médica percorre décadas tanto quanto suas "encruzilhadas". Nesse particular, o otimismo não basta (Paim, 1991). A prerrogativa constitucional de "ordenar a formação de recursos humanos", pode diluir-se em retórica se não for contemplada com uma explícita política de formação $e$ utilização de recursos humanos que aponte para as "regras do jogo" a médio e longo prazos.

Uma universidade e uma faculdade de medicina não são uma planta industrial capaz de alterar rápida e impunemente suas "linhas de montagem" ou flexibilizar seus processos produtivos mediante tecnologias modernas de ensino e terceirizações. Constituir sujeitos comprometidos com a vida $e$ a saúde dos cidadãos e protagonistas de um projeto radical de Reforma Sanitária representa uma missão que precisa ser bem compreendida para não resultar em equívocos e frustrações.

Um governo responsável, quando formula uma política ousada como aquela referente à expansão do PSF, precisaria explicitar mecanismos indutores de apoio às mudanças nas instituições educativas, entre os quais o financiamento dos programas, projetos e atividades.

\section{Comentários Finais}

Para que o PSF não fique confinado no "SUS para pobres" (Paim, 1995) e na "atenção primitiva de saúde" (Testa, 1992), faz-se necessário produzir cunhas no nível secundário e pontes com o nível terciário da atenção. Não deve permanecer exclusivamente nas áreas rurais ou nos guetos das cidades 
e os seus Pólos de Capacitação não merecem limitar-se a quistos de universidades, enquanto vitrines de mudanças virtuais. Para avançar em transformações a Saúde da Família precisa incomodar: demonstrar, a cada momento, que a maior proporção dos recursos financeiros e assistencias continua a ser destinada para a assistência hospitalar e para os procedimentos de média e alta complexidade, apesar da retórica da prioridade da atenção básica; $e$ aproveitar as oportunidades e contradições para incidir no plano estrutural de mudanças das instituições de ensino, promovendo alterações nos processos, nas relações e nos conteúdos da educação (Almeida, 1999).

Nessa perspectiva, entre os desafios para as práticas de formação e educação permanente encontra-se o de produzir uma nova consciência do sujeito público que integre os processos de construção contra-hegemônica e gere um novo pensamento e liderança capazes de propor uma nova maneira de hacer las cosas (Testa, 1997, p.156), contribuindo na construção da viabilidade de modelos assistenciais alternativos.

\section{Referências bibliográficas}

ALMEIDA, M.J. Educação médica e saúde: possibilidades de mudança. Londrina: UEL; Rio de Janeiro: ABEM, 1999. p.84-108.

BRASIL. Ministério da Saúde. Norma Operacional Básica SUS - 01/1993. Inf. Epidemiol. SUS, n. esp. p.49-73, 1993.

CORDEIRO, H. O PSF como estratégia de mudança do modelo assistencial do SUS. Cad. Saúde Família, v.1, p.10-5, 1996.

LEVCOVITZ, E., GARRIDO, N.G. Saúde da família: a procura de um modelo anunciado. Cad. Saúde Família, v.1, p.3-9, 1996.

OFFE, C. Problemas estruturais do Estado Capitalista. Rio de Janeiro: Tempo Brasileiro, 1994. p.140-77.

OPS. Desarrollo y fortalecimiento de los sistemas locales de salud en la transformacion de los sistemas nacionales de salud. In: PAGANINI, J.M., CAPOTE MIR, R. Los Sistemas Locales de Salud: conceptos, métodos, experiencias. Washington: OPS, 1990, p.5-20. (Publicación Científica, 519)

PAIM, J. S. Saúde, crises, reformas. Salvador: Centro Editorial e Didático da UFBA, 1986.

PAIM, J. S. Educación médica en la década de 1990: el optimismo no basta. Educ. Méd. Salud, v.25, n.1, p.48-57, 1991.

PAIM, J. S. A reorganização das práticas de saúde em distritos sanitários. In: MENDES, E. V. (Org.) Distrito sanitário: o processo social de mudança das práticas sanitárias do Sistema Único de Saúde. São Paulo: Hucitec; Rio de Janeiro: Abrasco, 1993. p.187-220.

PAIM, J. S. Formação médica e políticas de saúde. In: Congresso Brasileiro de Educação Médica, 33, 1995. Anais... Porto Alegre, 1995. p.247-61.

SCHRAIBER, L.B. (Org.) Programação em saúde, hoje. São Paulo: Hucitec, 1990.

SILVA JUNIOR, A.G. Modelos tecno-assistenciais em saúde: o debate no campo da Saúde Coletiva. São Paulo: Hucitec, 1998.

TESTA, M. Pensar em saúde. Porto Alegre: Artes médicas/ABRASCO, 1992.

TESTA, M. Saber en Salud. La construcción del conocimiento. Buenos Aires: Lugar Editorial, 1997. 